\title{
UM CASO DE INCONSTITUCIONALIDADE NO CONTROLE DIFUSO DE CONSTITUCIONALIDADE.
}

\author{
Gryecos Attom Valente Loureiro*
}

\begin{abstract}
Resumo
O sistema processual brasileiro de controle judicial de constitucionalidade, possibilita a coexistência de decisões judiciais que sejam antagônicas entre si, inclusive possibilitando distorções na aplicação coletiva de um direito fundamental, como no caso do princípio da isonomia tributária. O presente estudo visa demonstrar a possibilidade de coexistência de uma decisão judicial em controle difuso, definitiva, que cria vantagem tributária frente a outros contribuintes, com decisão judicial coletiva posterior, também em sede de controle de constitucionalidade, que não reconheça a existência do mesmo direito. O estudo reflete sobre esta aparente inconstitucionalidade no sistema processual.
\end{abstract}

Palavras-chave: Controle de Constitucionalidade; Direitos Fundamentais; Isonomia Tributária; Direito Processual; Inconstitucionalidade.

\section{ONE CASE OF UNCONSTITUTIONALITY ON THE JUDICIAL REVIEW.}

\begin{abstract}
The Brazilian procedural system of judicial review allows the coexistence of judicial decisions that are antagonistic to each other, including allowing distortions in the general enforcement of fundamental rights, as in the case of the principle of tax equality. The present study aims to demonstrate the possibility of coexistence of one judicial review decision, unappealable, that creates a tax advantage against other taxpayers in an identical situation, with a subsequent judicial review decision in a class action, which does not recognize the existence of the same fundamental right. The study reflects on this apparent unconstitutionality in the procedural system.
\end{abstract}

Keywords: Judicial review; Fundamental rights; Tax equality; Procedural law; Unconstitutionality.

\section{Introdução}

O controle judicial de constitucionalidade das normas é uma realidade no direito brasileiro, contribuindo para a efetivação das garantias fundamentais do indivíduo.

\footnotetext{
* Doutorando em Direito Constitucional no IDP/DF (2019). Mestre em Hermenêutica e Direitos Fundamentais pela UNIPAC/MG-JF (2014). Especialista em Direito Processual Civil pela UNISC/RS (2010) e Especialista (MBA) em Direito Empresarial pela FGV/RJ (2004). Graduado em Ciências Jurídicas e Sociais pela UFRJ (1998). Professor licenciado do UGB/RJ. Professor convidado no IDP/DF e UDF/DF. Advogado concursado da Caixa Econômica Federal. Diretor Jurídico da CAIXA desde 2018. gryecos@ gmail.com
} 
A evolução dos direitos processual e constitucional tem proporcionado estudos, debates e intensa produção acadêmica sobre o tema, com evidentes reflexos na transformação da jurisprudência nas últimas três décadas pós-constituição de 1988.

A despeito de existirem estudos e debates acadêmicos pretendendo rediscutir e resignificar o tema, fato é que nosso modelo pressupõe a constituição como a nossa lei maior e como o fundamento de validade de todo o ordenamento jurídico brasileiro.

Neste sentido, a doutrina do controle de constitucionalidade (judicial review), nascida no direito norte-americano e incorporada na legislação brasileira, se apresenta como a alternativa judicial de garantia da higidez de nossa constituição.

Para os fins do presente estudo, admitiremos que o controle judicial de constitucionalidade das normas só exista para garantir a solidez do texto constitucional, enquanto Lei Maior de nosso ordenamento jurídico, e que os corolários desta garantia sejam a proteção e a efetivação dos direitos fundamentais.

Ocorre que pelo sistema processual vigente, existem possibilidades nas quais decisões judiciais em controle de constitucionalidade possam vir a ser antagônicas entre si, o que, por si só, se constitui em um problema que mereceria solução.

De forma ainda mais provocativa, propomos que haverá hipóteses nas quais será possível observar a coexistência de decisões antagônicas em sede de controle de constitucionalidade, podendo criar distorções na aplicação coletiva de um direito fundamental, como no caso do princípio da isonomia tributária. A toda evidência, esta possibilidade faz com que o problema seja revestido de contornos ainda mais acentuados.

Sob esta ótica, fixaremos mira na ofensa à constituição criada por uma decisão judicial em controle difuso, soberanamente transitada em julgado, cujo efeito no mundo fenomenológico seja criar vantagem tributária frente a outros contribuintes em situação idêntica, que nada poderão fazer, diante da existência de decisão judicial posterior, que não lhes reconheça a existência do mesmo direito.

No primeiro caso hipotético, reconheceu-se a inconstitucionalidade da norma tributária e, no segundo, reconheceu-se a sua constitucionalidade para todos os demais contribuintes em idêntica situação. No primeiro, cessou-se a exação. No segundo, a cobrança permanecerá.

Importante registrar que a inquietação que provocou o presente estudo, adveio da primeira leitura ao trabalho desenvolvido por Scaff (2015), que traz luz ao reflexo pragmático 
potencialmente nocivo existente na sistemática do controle difuso de constitucionalidade no Brasil.

Destacamos, outrossim, que em Waldron (2006) também há referência a existência de críticas ao controle judicial de constitucionalidade ${ }^{2}$, mesmo em sua terra natal.

Vale o registro de que a hipótese apresentada na presente pesquisa pode também vir a ser dirimida pelo STF, na medida em que existem dois Temas ${ }^{3}$ potencialmente relacionados, hoje afetados na sistemática da repercussão geral, pendentes de julgamento naquela Corte Maior.

Considerando a delimitação dos Temas afetados, parece-nos que os objetos das teses porventura advindas do julgamento do STF não abrangerão a integralidade do risco apontado na presente pesquisa.

Além disso, não se pode descurar que o conflito entre eventuais decisões judiciais pode não envolver o STF, podendo restar a questão esgotada em instância inferior.

O conflito de decisões em controle difuso também pode alcançar contribuintes que estejam em igualdade tributária, como, por exemplo, quando a decisão de inconstitucionalidade tiver sido proferida em uma ação individual e a posterior decisão de constitucionalidade for proferida em uma ação coletiva.

Portanto, ainda que seja evidente que os futuros julgamentos dos Temas 733 e 881 pelo STF trará luz e novos contornos para a hipótese, parece-nos que diante da delimitação apresentada pelos senhores Ministros, a presente pesquisa tem o potencial de permanecer interessante mesmo após as manifestações plenárias.

\footnotetext{
2 "In recente years, a number of books have appeared attacking judicial review in America For years, support for the practice has come from liberals, and opposition from conservative opponents of the rights that liberal courts have upheld. In recent years, however, we have seen the growth of liberal opposition to judicial review, as the Rehnquist Court struck down some significant achievements of liberal legislative policy. But there have been spirited defenses of the practice as well. The two-hundredth anniversary of Marbury v. Madison elicited numerous discussions of its origins and original legitimacy, and the fiftieth anniversary of Brown v. Board of Education provided a timely reminder of the service that the nation's courts performed in the mid-twentieth century by spearheading the attack on segregation and other racist laws."

${ }^{3}$ Brasil. STF. Tema 733: "A decisão do Supremo Tribunal Federal declarando a constitucionalidade ou a inconstitucionalidade de preceito normativo não produz a automática reforma ou rescisão das decisões anteriores que tenham adotado entendimento diferente. Para que tal ocorra, será indispensável a interposição de recurso próprio ou, se for o caso, a propositura de ação rescisória própria, nos termos do art. 485 do CPC, observado o respectivo prazo decadencial (art. 495). (Relator Min Roberto Barroso - Leading Case, RE 955.227).
}

Tema 881: Limites da coisa julgada em matéria tributária, notadamente diante de julgamento, em controle concentrado pelo Supremo Tribunal Federal, que declara a constitucionalidade de tributo anteriormente considerado inconstitucional, na via do controle incidental, por decisão transitada em julgado. (Relator Min. Edson Fachin - Leading Case RE 949297). 
Diante deste quadro introdutório, a indagação provocativa que exsurge da proposição é a seguinte: a possibilidade de que o controle de constitucionalidade difuso gere decisões antagônicas, criando situações concretas de proteção e não proteção constitucional para pessoas ou grupos de pessoas em situação idêntica, eiva de inconstitucionalidade o próprio instituto do controle difuso?

\section{Controle judicial de constitucionalidade no Brasil}

Pensar em controle judicial de constitucionalidade das normas é admitir, ab ovo, que a constituição ocupa uma posição destacada e superior sobre todo o ordenamento jurídico. De uma forma introdutória e considerando a constituição como uma espécie de liame subjetivo, de amálgama que unifica o direito positivo, Sarmento (2002, p. 28) considera que

[...] Por tal razão, é a Constituição, como fonte de validade de todas as normas, que confere a necessária coesão ao ordenamento jurídico.

Mas, se é na Constituição que repousa a unidade da ordem jurídica, a idéia de unidade também se projeta sobre ela. Assim, a busca da harmonia entre diferentes ditames constitucionais é uma tarefa que se impõe a qualquer um que pretenda interpretar a Lei Fundamental ou aplica-la a casos concretos.

Segundo o autor, portanto, a harmonia é o critério hermenêutico que deve estar presente quando se trata de aplicar a constituição a casos concretos. Podemos dizer, em seguimento, que a harmonia deve estar presente não apenas no necessário cotejo entre as peculiaridades do caso concreto e o texto constitucional, não apenas entre um aspecto específico da constituição e a coerente unidade do todo, mas também em face dos reflexos da decisão para os demais jurisdicionados, inclusive àqueles não abrangidos pelo mandamento que se extrairá do processo judicial.

Neste mesmo sentido, e nomeando a jurisdição como a função estatal pacificadora (CINTRA, GRINOVER E DINAMARCO, 1996, p. 24-25), a obra que é uma das referências em teoria do processo no direito brasileiro estabelece que

A pacificação é o escopo magno da jurisdição e, por consequência, de todo o sistema processual [...]

É para a consecução dos objetivos da jurisdição e particularmente daquele relacionado com a pacificação com justiça, que o Estado institui o sistema processual, ditando normas a respeito (direito processual), criando órgãos jurisdicionais, fazendo despesas com isso e exercendo através dela o seu poder. 
[...] Afirma-se que o objetivo-síntese do Estado contemporâneo é o bemcomum e, quando se passa ao estudo da jurisdição, é lícito dizer que a projeção particularizada do bem comum nessa área é a pacificação com justiça.

No Brasil vige o sistema que congrega tanto o controle de constitucionalidade chamado concentrado, ou abstrato, quanto o difuso, ou concreto (MORAES, 2001, p. 565)

\begin{abstract}
9.1 Difuso ou aberto
Também conhecido como controle por via de exceção ou defesa, caracterizase pela permissão a todo e qualquer juiz ou tribunal realizar no caso concreto a análise sobre a compatibilidade do ordenamento jurídico com a Constituição Federal. [...] Na via de exceção, a pronúncia do Judiciário, sobre a inconstitucionalidade, não é feita enquanto manifestação sobre o objetivo principal da lide, mas sim sobre questão prévia, indispensável ao julgamento do mérito. [...] Entretanto, este ato ou lei permanecem válidos no que se refere à sua força obrigatória com relação a terceiros.

[...] 9.2 Controle concentrado ou via de ação direta

[...] procura-se obter a declaração de inconstitucionalidade de lei ou do ato normativo em tese, independentemente da existência de um caso concreto, visando-se à obtenção da invalidade da lei [...]. A declaração da inconstitucionalidade, portanto, é o objeto principal da ação.
\end{abstract}

Analisando especificamente sobre a ótica processual, e ainda sob a égide do Código Buzaid, Alexandre Câmara (2002, p. 35-36) rumou na mesma linha descrita acima pelo atual Ministro do STF

No controle concentrado, exercido pelo Supremo Tribunal Federal (e pelos Tribunais de Justiça dos Estados) [...] analisa-se, como objeto do processo, a compatibilidade ou não da lei ou ato normativo (ou, no caso da inconstitucionalidade por omissão, a falta de lei ou de ato normativo) com a Constituição da República. A decisão a ser proferida pelo STF irá operar erga omnes, afirmando a constitucionalidade ou inconstitucionalidade da norma jurídica analisada.

Já o controle difuso da constitucionalidade pode ser exercido por qualquer órgão jurisdicional, em qualquer processo instaurado, sendo certo que nesta modalidade a questão da constitucionalidade da lei ou ato normativo não constitui o objeto do processo, mas sim questão prejudicial.

Espera-se do Poder Judiciário, como regra de ouro, que sempre se manifeste com isenção e com o adequado distanciamento dos interesses antagônicos discutidos no seio de um processo judicial. Registramos, todavia, que aqui não temos o objetivo de diferenciar a natureza processual objetiva existente em uma ação direta, por exemplo, ou mesmo a inexistência de partes contendoras, como na tradicional relação processual angular. 
Por outro lado, pretendemos trazer luz para a necessidade de manutenção desta esperada isenção do julgador, especialmente pelos reflexos evidentes advindos do controle judicial de constitucionalidade.

Acerca do ponto, inclusive, vale traçar um paralelo entre a necessária imparcialidade do juiz e a teoria dos Poderes Neutrais do Estado (ARAGÃO, 2001 p. 24) e recupera a história para afirmar que contemporaneamente a Revolução Francesa, se acreditava que apenas os órgãos ocupados por mandatários eleitos - oriundos da soberania popular, portanto - poderiam regular a vida em sociedade, mas que

\begin{abstract}
Logo, porém, foi verificada a necessidade de criação de órgãos estatais com autonomia de gestão e independência funcional para, fora do círculo políticoeleitoral, controlar e equilibrar as relações entre os titulares dos cargos eletivos para assegurar a observância dos valores maiores da coletividade. Surgiram, então, os poderes neutrais do Estado, que abrangem realidades díspares, desde as cortes constitucionais às agências reguladoras independentes, passando pelos tribunais de contas, conselhos com sede constitucional, etc.
\end{abstract}

A responsabilidade do julgador, por sua vez, ganha contornos de beleza literária nas palavras de Cappelletti (1992, p. 130)

[...] Na verdade, na concepção moderna, a norma constitucional outra coisa não é senão a tentativa - talvez impossível, talvez "faustiana", mas profundamente humana - de transformar em direito escrito os supremos valores, a tentativa de recolher, de "definir", em sua, em uma norma positiva, o que, por sua natureza, não se pode recolher, não se pode definir - o Absoluto. A justiça constitucional é a garantia desta "definição"; mas é também, ao mesmo tempo, o instrumento para torná-la aceitável, adaptando-a às concretas exigências de um destino de perene mutabilidade.

Para os fins desta "relativização", desta "positivação" do Absoluto, o engenho criativo do homem descobriu, precisamente na justiça constitucional, o instrumento mais refinado, mais aperfeiçoado, embora sujeito, como todos os instrumentos humanos, a erros, variações, defeitos.

Parece-nos evidente, portanto, que no momento histórico no qual nos encontramos e diante da evolução dos direitos processual e constitucional, especialmente no que tange ao reconhecimento de que o controle judicial de constitucionalidade das normas é corolário do Estado de direito, do Estado regulado pelo império da lei, não há espaço de tolerância para admitirmos que neste processo de judicial review seja possível admitir situações nas quais uma garantia constitucional seja relegada para segundo plano.

Aqui, neste locus hermenêutico, os benefícios da existência de um processo regulado e de procedimentos previamente definidos, não são capazes de absolver eventual deslize 
pragmático ou inconsistência do sistema, que culmine com a negativa de validade de qualquer garantia constitucional.

\section{Controle difuso - Permanente risco de inconstitucionalidade}

Ainda que a inspiração para a presente investigação tenha partido do trabalho desenvolvido por Scaff (2015), conforme citado, o fato concreto é que Cappelletti (1992, p. 130) já havia alertado sobre os grandes riscos de se introduzir o sistema do controle difuso, ou "americano", criado sob a inteligência da commom law, no chamado "sistema europeu", de tradição de civil law e, portanto, sem a figura do stare decisis. A evidência se extrai das letras do original, quando afirma que

[...] a introdução, nos sistemas de civil law, do método "americano" de controle, levaria à consequência de que uma lei ou disposição de lei poderia não ser aplicada, porque julgada inconstitucional, por alguns juízes, enquanto poderia, ao invés, ser aplicada, porque não julgada em contraste com a Constituição, por outros. Demais, poderia acontecer que o mesmo órgão judiciário que, ontem, não tinha aplicado uma determinada lei, ao contrário, a aplique hoje, tendo mudado de opinião sobre o problema de sua legitimidade constitucional. Poderiam, certamente, formar-se verdadeiros "contrastes de tendências" entre órgãos judiciários de tipo diverso.

A conclusão de que a introdução do sistema de controle difuso num país de tradição romano-germânica, como o Brasil, não seria uma boa opção, já era antevista por Cappelletti (1992, p. 77-78), na medida em que o professor registrou o perigo das consequências, há pouco mais de cinquenta anos, quando afirmou que

[...] A consequência, extremamente perigosa, de tudo isto, poderia ser uma grave situação de conflito entre órgãos e de incerteza do direito, situação perniciosa quer para os indivíduos como para a coletividade e o Estado.

[...] Mas não basta. Ulteriores inconvenientes do método "difuso" de controle [...] são os que derivam da necessidade de que, mesmo depois de uma primeira não aplicação ou de uma série de não aplicações de uma determinada lei por parte das Cortes, qualquer sujeito interessado na não aplicação da mesma lei proponha, por sua vez, um novo caso em juízo.

Importante registrar que o Código de Processo Civil de 2015 (CPC) ${ }^{4}$, trouxe diversos avanços na seara do controle judicial de constitucionalidade das normas, especialmente quanto a incorporação de institutos típicos do direito norte-americano.

\footnotetext{
${ }^{4}$ Brasil. Lei 13.105 de 16 de março de 2015.
} 
Todavia, a hipótese tratada na presente pesquisa, ou seja, a possibilidade de que uma decisão judicial em controle difuso, soberanamente julgada, que reconhece a inconstitucionalidade de lei, permaneça válida e produza efeitos, ainda que sobrevenha decisão posterior de qualquer órgão jurisdicional superior, inclusive do Supremo Tribunal Federal, seja em controle difuso ou concentrado, que reconheça a constitucionalidade da norma, permanece viva no sistema brasileiro.

Nesta hipótese de estudo, caso a decisão em controle difuso tenha proporcionado o fim de determinada exação, o contribuinte beneficiado competirá no mercado em condições mais benéficas que seus concorrentes.

A conclusão que nos parece consequente e inexorável, portanto, é que teríamos uma situação de ofensa ao princípio constitucional da isonomia tributária ${ }^{5}$ e uma ofensa ao postulado da livre concorrência ${ }^{6}$.

\subsection{O cenário após a edição do CPC de 2015}

Faz-se necessário registrar a tentativa de solução do imbróglio, trazida pelo CPC de 2015.

O Estatuto processual se dedicou a criar disposições específicas para a fase de cumprimento de sentença envolvendo obrigação de pagar quantia certa para o particular e, de forma análoga, dedicou regra específica para a Fazenda Pública.

Para o particular, o CPC positivou a disposição com a redação do art. $525, \S 15^{7}$.

\footnotetext{
${ }^{5}$ Brasil. Constituição Federal. Art. 5. Art. $5^{\circ}$ Todos são iguais perante a lei, sem distinção de qualquer natureza, garantindo-se aos brasileiros e aos estrangeiros residentes no País a inviolabilidade do direito à vida, à liberdade, à igualdade, à segurança e à propriedade, nos termos seguintes: [...]

Art. 150. Sem prejuízo de outras garantias asseguradas ao contribuinte, é vedado à União, aos Estados, ao Distrito Federal e aos Municípios: [...]

II - instituir tratamento desigual entre contribuintes que se encontrem em situação equivalente, proibida qualquer distinção em razão de ocupação profissional ou função por eles exercida, independentemente da denominação jurídica dos rendimentos, títulos ou direitos;

${ }^{6}$ Brasil. Constituição Federal. Art. 170. A ordem econômica, fundada na valorização do trabalho humano e na livre iniciativa, tem por fim assegurar a todos existência digna, conforme os ditames da justiça social, observados os seguintes princípios: [...] IV - livre concorrência;

${ }^{7}$ Art. 525. Transcorrido o prazo previsto no art. 523 sem o pagamento voluntário, inicia-se o prazo de 15 (quinze) dias para que o executado, independentemente de penhora ou nova intimação, apresente, nos próprios autos, sua impugnação.

$\S 1^{\circ} \mathrm{Na}$ impugnação, o executado poderá alegar:

[...]III - inexequibilidade do título ou inexigibilidade da obrigação; [...]

$\S 12$. Para efeito do disposto no inciso III do $\S 1^{\circ}$ deste artigo, considera-se também inexigível a obrigação reconhecida em título executivo judicial fundado em lei ou ato normativo considerado inconstitucional pelo
} 
Para a Fazenda Pública, dedicou o art. $535, \S 8^{\circ}$.

Antes de analisarmos as disposições citadas no CPC de 2015, e o posicionamento do STF sobre ambas, convém abrir um parêntese reflexivo, partindo da premissa de que tais regras estariam válidas e seriam aplicáveis sem ressalvas.

Pois bem. Agora dentro do parêntese, brota a seguinte indagação: Com a previsão inserta nos artigos citados, ou seja, com a possibilidade de se rescindir a decisão em controle difuso, caso sobrevenha decisão do Supremo Tribunal Federal em sentido diverso, o problema apresentado na presente pesquisa estaria resolvido?

Não nos parece que a resposta seja positiva, infelizmente.

Nossa proposição inicial foi de que a manutenção da decisão em controle difuso, exemplificada acima, ofenderia os princípios de tratamento isonômico entre os contribuintes e a própria livre concorrência mencionados.

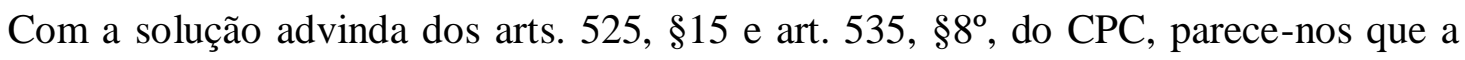
novel e superveniente modificação foi apenas no foco da ofensa ao texto constitucional. Desta

Supremo Tribunal Federal, ou fundado em aplicação ou interpretação da lei ou do ato normativo tido pelo Supremo Tribunal Federal como incompatível com a Constituição Federal, em controle de constitucionalidade concentrado ou difuso.

$\S 13$. No caso do $\S 12$, os efeitos da decisão do Supremo Tribunal Federal poderão ser modulados no tempo, em atenção à segurança jurídica.

$\S$ 14. A decisão do Supremo Tribunal Federal referida no $§ 12$ deve ser anterior ao trânsito em julgado da decisão exequenda.

$\S 15$. Se a decisão referida no $§ 12$ for proferida após o trânsito em julgado da decisão exequenda, caberá ação rescisória, cujo prazo será contado do trânsito em julgado da decisão proferida pelo Supremo Tribunal Federal.

${ }^{8}$ Art. 535. A Fazenda Pública será intimada na pessoa de seu representante judicial, por carga, remessa ou meio eletrônico, para, querendo, no prazo de 30 (trinta) dias e nos próprios autos, impugnar a execução, podendo arguir: $[\ldots]$

III - inexequibilidade do título ou inexigibilidade da obrigação; [...]

$\S 5^{\circ}$ Para efeito do disposto no inciso III do caput deste artigo, considera-se também inexigível a obrigação reconhecida em título executivo judicial fundado em lei ou ato normativo considerado inconstitucional pelo Supremo Tribunal Federal, ou fundado em aplicação ou interpretação da lei ou do ato normativo tido pelo Supremo Tribunal Federal como incompatível com a Constituição Federal , em controle de constitucionalidade concentrado ou difuso.

$\S 6^{\circ}$ No caso do $\S 5^{\circ}$, os efeitos da decisão do Supremo Tribunal Federal poderão ser modulados no tempo, de modo a favorecer a segurança jurídica.

$\S 7^{\circ}$ A decisão do Supremo Tribunal Federal referida no $\S 5^{\circ}$ deve ter sido proferida antes do trânsito em julgado da decisão exequenda.

$\S 8^{\circ}$ Se a decisão referida no $\S 5^{\circ}$ for proferida após o trânsito em julgado da decisão exequenda, caberá ação rescisória, cujo prazo será contado do trânsito em julgado da decisão proferida pelo Supremo Tribunal Federal. 
feita, a mácula repousaria sobre a proteção da garantia fundamental de proteção da coisa julgada (art. $5^{\circ}, \mathrm{XXXVI}^{9}$ ). Teríamos por ofendido, portanto, o princípio da segurança jurídica.

Não por outra razão, os referidos dispositivos do CPC foram "reflexamente afastados" do ordenamento jurídico pelo Supremo Tribunal Federal ${ }^{10}$, posto que apesar de reconhecer a constitucionalidade dos artigos, negou validade aos $\S \S 15$ e $8^{\circ}$, respectivamente, ao estabelecer a condicionante "desde que, em qualquer dos casos, o reconhecimento dessa constitucionalidade ou a inconstitucionalidade tenha decorrido de julgamento do STF realizado em data anterior ao trânsito em julgado da sentença exequenda".

Em outras palavras, o que pretendemos dizer é que ao reconhecer a constitucionalidade modulada dos $\S \S 12$ e 14, c/c inciso III, do $\S 1^{\circ}$, art. 525, e do $\S 5^{\circ}$, art. 535, do CPC, o STF não permitiu nenhuma leitura possível para o $§ 15$, do mesmo art. 525 e para o $\S 8^{\circ}$ do citado art. 535.

Cumpre-nos registrar, entretanto, que durante a apreciação da mencionada ADI 2418/18, o STF não se debruçou especificamente sobre os citados $\S 15$, do art. 525 e $\S 8^{\circ}$ do art. 535. Da mesma forma, não identificamos registro na doutrina que referende a proposição apresentada no presente estudo. Trata-se de conclusão livre advinda da presente pesquisa, sujeita a censura.

Vale ainda o registro de que o CPC também cuidou de garantir que a coisa julgada recebesse proteção quando houvesse a apreciação de matéria constitucional em sede de controle difuso, quando tal manifestação jurisdicional ocorresse no âmbito do juízo monocrático, na instância de piso. Parece-nos, em observação perfunctória, que a previsão do art. 503, $\S 1^{\circ}$, III (art. 502) ${ }^{11}$, contrasta sistemicamente com as previsões acima citadas ${ }^{12}$.

Identificamos registro na doutrina sobre a sutileza inserta pelo legislador quanto ao prestígio da coisa julgada (DELLORE, 2019) e não propriamente quanto a sua relativização.

\footnotetext{
${ }^{9}$ Brasil. Constituição Federal. Art. $5^{\circ}$ Todos são iguais perante a lei, sem distinção de qualquer natureza, garantindo-se aos brasileiros e aos estrangeiros residentes no País a inviolabilidade do direito à vida, à liberdade, à igualdade, à segurança e à propriedade, nos termos seguintes: [...] XXXVI - a lei não prejudicará o direito adquirido, $\mathrm{O}$ ato jurídico perfeito e a coisa julgada;

${ }_{11}^{10}$ Brasil. STF. ADI 2418/DF. Dje em 17/11/2016 - ATA No 175/2016. Dje no 243, divulgado em 16/11/2016.

${ }^{11}$ Brasil. Lei 13.105/2015. Art. 502. Denomina-se coisa julgada material a autoridade que torna imutável e indiscutível a decisão de mérito não mais sujeita a recurso.

Art. 503. A decisão que julgar total ou parcialmente o mérito tem força de lei nos limites da questão principal expressamente decidida.

$\S 1^{\circ} \mathrm{O}$ disposto no caput aplica-se à resolução de questão prejudicial, decidida expressa e incidentemente no processo, se: [...] III - o juízo tiver competência em razão da matéria e da pessoa para resolvê-la como questão principal.

${ }^{12}$ Brasil. Lei 13.105/2015. Arts. 525, §15 e 535, §8.
} 
Com efeito, a norma deixa claro que os arts. 525 e 535, e seus parágrafos, tratam de inexigibilidade do título executivo por força de controle difuso ou concentrado, mas estabelece que esta inexigibilidade não será uma consequência natural do procedimento. Há que se trilhar, portanto, o tortuoso caminho da ação rescisória e, por conseguinte, submeter-se a novo escrutínio judicial.

Por fim, não há que se falar em utilização do instituto da Reclamação, na medida em que a própria dicção processual impossibilita ${ }^{13}$ tal expediente, na medida em que nossa problemática estabelece como premissa que a decisão em sede de controle difuso teria transitado em julgado antes da decisão do Supremo Tribunal Federal.

Diante do cenário apresentado, parece-nos, a toda evidência, que a hipótese escolhida para nosso estudo permaneceu intocada pelo novo regramento processual civil, segundo a intelecção advinda da lupa do STF.

\subsection{Alternativa para uma possível constitucionalidade}

A trilha racional que vimos percorrendo até o momento, não apresenta um horizonte alvissareiro para o instituto do controle difuso no Brasil, ao menos não para a hipótese específica tratada no presente estudo.

Aliás, como vimos anteriormente em Cappelletti (1992), desde o princípio era previsto que a inserção do modelo difuso, que é típico dos sistemas de tradição de commom law, em países de tradição romano-germânica, e de civil law, portanto, enfrentaria muitas dificuldades para performar adequadamente.

A inexistência de um sistema de precedentes e da incorporação de institutos como o stare decisis, o distinguishing e o overruling, num sistema de civil law, como o brasileiro, já era identificado como os maiores empecilhos pelo professor italiano há mais cinquenta anos.

\footnotetext{
${ }^{13}$ Art. 988. Caberá reclamação da parte interessada ou do Ministério Público para: [...]

III - garantir a observância de enunciado de súmula vinculante e de decisão do Supremo Tribunal Federal em controle concentrado de constitucionalidade; [...]

$\S 5^{\circ}$ É inadmissível a reclamação:

I - proposta após o trânsito em julgado da decisão reclamada;

II - proposta para garantir a observância de acórdão de recurso extraordinário com repercussão geral reconhecida ou de acórdão proferido em julgamento de recursos extraordinário ou especial repetitivos, quando não esgotadas as instâncias ordinárias.
} 
O Código de Processo Civil de 2015, entretanto, trouxe inegáveis avanços na introdução destes elementos, típicos do direito anglo-saxão, para o processo civil brasileiro, possibilitando que uma pequena chama pudesse ser enxergada no fim deste túnel exegético.

Em nosso sentir, a solução proposta para o problema apresentado nesta pesquisa, entretanto, não foi a adequada.

Não nos parece compatível com a proteção constitucional da coisa julgada, como corolário da garantia de segurança jurídica, que toda e qualquer decisão judicial lastreada em interpretação que posteriormente, em um futuro sem limitação temporal, venha a ser modificada pelo STF, possa ser desafiada via ação rescisória.

A insegurança não repousaria apenas sobre os ombros dos jurisdicionados, mas também teria o potencial de constituir pesada âncora limitadora aos julgadores do próprio STF, na medida em que a modificação de uma jurisprudência passaria, possivelmente, pela avaliação sobre a quantidade de relações jurídicas já julgadas que seriam afetadas.

Todavia, a questão talvez não seja inteiramente insolúvel.

Já que a abordagem do CPC foi rechaçada pelo próprio STF, ou seja, a abordagem que criava a insegurança jurídica de que qualquer decisão pudesse ser rescindida no futuro, caso a avaliação de constitucionalidade do STF fosse modificada, talvez possamos inverter a lógica.

Parece-nos, com a honesta modéstia de quem apresenta uma proposta ainda em análise inicial e sem os apropriados debates sobre o tema, que melhor seria que toda a decisão em sede de controle difuso de constitucionalidade fosse analisada pelo STF.

Assim como um caso de reexame necessário, o STF sempre daria a última palavra em sede de controle judicial de constitucionalidade.

Importante ressalva, reside no ponto de que a proposta não tem a pretensão de trazer em si mais uma avalanche de processos ao Tribunal Supremo. Não se trata de mais uma competência recursal do STF.

Em regra, trata-se, isso sim, de reexame apenas de questões que tivessem a analise meritória de constitucionalidade pelos Tribunais inferiores. A possibilidade de decisões monocráticas nos juízos de primeira instância, que tenham transitado em julgado, também seriam submetidas ao reexame, para dar coerência ao instituto. Não nos parece, entretanto, que este último exemplo represente número expressivo de julgados, de molde a inviabilizar numericamente a proposta. 
Ademais, aqui não se trata de mera e salutar divergência na jurisprudência, típica da garantia de independência que todo julgador deve usufruir. O que estamos analisando é a manifestação do Poder Judiciário sobre a constitucionalidade de uma norma. Conviver com divergência de entendimento sobre a constitucionalidade de uma norma é subverter, em boa medida, toda a estrutura jurídica que atribui à constituição federal a sua posição de Lei Maior.

Neste ponto da escalada, aproximamo-nos da avaliação de Dellore (2013, p. 369), na medida em que

[...] é inegável que existem dúvidas a respeito da verdadeira natureza de nosso modelo misto [...] a única certeza que se tem é que as respostas clássicas que a doutrina trazia para os problemas envolvendo o controle de constitucionalidade já não são mais suficientes para interpretar o fenômeno em sua inteireza.

A proposta, ainda que existente apenas no âmbito intuitivo, dialoga, ou tem o potencial de dialogar, com o movimento que se tem chamado de objetivação do processo. Com efeito, parece que a evolução do processo civil brasileiro aponta para esta direção, o que fica mais evidente quando o professor Osmar Paixão Côrtes (2016) esclarece que

\footnotetext{
Observa-se, há alguns anos, no âmbito principalmente dos Tribunais Superiores, uma mudança de paradigma - do subjetivo ao objetivo. As Cortes focam mais sua atuação na definição de teses (objetivo) que surtirão efeitos em outros processos (subjetivo). As decisões tomadas pelos tribunais, ainda que não em processos típicos de controle concentrado (objetivos), produzem efeitos para além do caso concreto e afetam outros processos (subjetivos).

A esse movimento, chama-se objetivação.
}

Nosso objetivo foi enunciar o problema, identificar o que nos parece estar equivocado e, por que não, trazer um caminho de saída para reflexão. Se a pesquisa merecer críticas, nosso objetivo terá sido alcançado.

\section{Conclusão}

O controle judicial de constitucionalidade das leis é utilizado no Brasil, como referendo e corolário à hierarquia superior da Constituição Federal sobre todo o ordenamento jurídico.

O Brasil adota um sistema híbrido de controle judicial de constitucionalidade, utilizando os chamados controle concentrado, ou abstrato e o difuso, ou concreto. 
Em suas versões clássicas, podemos dizer que o sistema de controle concentrado possui contornos que o amoldam melhor a países de tradição civil law, enquanto o controle difuso está relacionado à inteligência advinda do commom law.

Em sua aplicação prática, há pelo menos uma hipótese na qual o sistema brasileiro permitiria que uma decisão inconstitucional permanecesse produzindo efeitos no ordenamento jurídico, sem que haja remédio processual para solucionar o problema.

A hipótese de inconstitucionalidade que identificamos, é aquela criada por uma decisão judicial em controle difuso, soberanamente transitado em julgado, que tenha por razão de decidir o reconhecimento da inconstitucionalidade de lei federal tributária, inserida em um cenário no qual posteriormente haja o reconhecimento de constitucionalidade da mesma norma tributária, criando exação para os demais contribuintes em situação idêntica ao beneficiário da primeira decisão.

Tal situação, gera frontal ofensa ao texto constitucional, seja na faceta do princípio da isonomia tributária, seja quanto ao primado da livre concorrência.

Apresentamos o entendimento, ainda que sem amparo expresso no acórdão da AI 2418/DF e na doutrina pesquisada, que a solução criada pelo CPC de 2015 é incompatível com o julgamento realizado pelo STF. Sustentamos ainda, ademais, que mesmo que os dispositivos estivessem vigentes (ou ainda que estejam vigentes) que a solução do CPC não apresenta resposta satisfatória para o problema apontado.

Ao permitir o desafio atemporal via ação rescisória, cujo termo a quo de exercício seria uma novel, hipotética e futura decisão do STF, o foco da ofensa constitucional passaria a ser o princípio da segurança jurídica, esculpido na forma da proteção constitucional à coisa julgada.

Uma solução possível, construída ainda em nível de mera e incipiente intuição, seria criar o reexame necessário, pelo STF, de todas as decisões em sede controle difuso.

A importância para a higidez da racionalidade de nosso sistema jurídico constitucionalidade da norma e produção de efeitos pragmáticos - justificaria essa atribuição ao guardião último de nossa Lei Maior. 


\section{REFERÊNCIAS}

ARAGÃO, Alexandre Santos de. O controle da constitucionalidade pelo Supremo Tribunal Federal à luz da teoria dos poderes neutrais. In: SARMENTO, Daniel. (Org.). O controle de constitucionalidade e a lei 9.868/99. Rio de Janeiro: Lúmen Juris, 2001.

Brasil. Constituição Federal, de 05 de outubro de 1988.

Lei 13.105 , de 16 de março de 2015.

STF. ADI 2418/DF. Dje em 17/11/2016 - ATA No 175/2016. Dje no 243, divulgado em 16/11/2016.

CÂMARA, Alexandre Freitas. Lições de direito processual civil. Vol. II. $6^{\mathrm{a}}$ ed. rev. e atual. Rio de Janeiro: Lúmen Juris, 2002.

CAPPELLETTI, Mauro. O controle judicial de constitucionalidade das leis no direito comparado. Trad. Aroldo Plínio Gonçalves. Rev. José Carlos Barbosa Moreira. 2 ed. Porto Alegre: Sergio Antonio Fabris Editor, 1992.

CINTRA, Antônio Carlos de Araújo; GRINOVER, Ada Pellegrini; DINAMARCO, Cândido Rangel. Teoria Geral do Processo. $12^{\mathrm{a}}$ ed. rev. e atual. São Paulo: Malheiros, 1996.

CÔRTES, Osmar Mendes Paixão. A objetivação do processo e o ativismo judicial no contexto do pós-positivismo. Revista de Processo. REPRO Vol. 151 (Janeiro de 2016).

DELLORE, Luiz Guilherme. Estudos sobre coisa julgada e controle de constitucionalidade. Rio de Janeiro: Forense, 2013.

O fim da relativização da coisa julgada no Novo $C P C$.

Disponível na internet: <http://www.jota.info/opiniao-e-analise/colunas/novo-cpc/o-fim-darelativizacao-da-coisa-julgada-no-novo-cpc-31082015>. Acesso em: 02 de junho de 2019.

MORAES, Alexandre de. Direito constitucional. 9a ed. atual. São Paulo: Atlas S/A, 2001.

SARMENTO, Daniel. A ponderação de interesses na constituição federal. Rio de Janeiro: Lúmen Juris, 2002.

SCAFF, Fernando Facury. Efeitos da Coisa Julgada em Matéria Tributária e Livre Concorrência. Cadernos da Escola de Direito e Relações Internacionais da UNISUL. Jan/dez. 2015.

WALDROW, Jeremy. The core of the case against judicial review. 115 Yale Law Journal 1346. April 2006, p. 3. 